\title{
Covenant Lite Lending, Liquidity and Standardization of Financial Contracts
}

\author{
Kenneth Ayotte \\ Patrick Bolton* \\ Northwestern University School of Law \\ Columbia Business School
}

December 2009

${ }^{*}$ We would like to thank Henry Smith and Ed Morrison for helpful feedback on this draft. Ayotte

also thanks the Searle Center on Law, Regulation and Economic Growth and the Ewing Marion Kauffman Foundation for generous research support. 


\section{Introduction}

The last decade has witnessed many rapid changes in corporate financial practice. Perhaps most important among these changes is the expansion of securitization practice to corporate loans. Through securitization, corporate loans are originated and sold into investment vehicles that issue securities called Collateralized Loan Obligations (CLOs). A common justification for securitization is that it allows for otherwise illiquid corporate loans to be transformed into more liquid securities that can be easily traded in secondary markets. ${ }^{1}$

Though the channel through which this "liquidity creation" occurs is not fully understood, a common explanation is that the process of pooling a large volume of loans allows third-party rating agencies, and the asset managers that assemble these pools, to create standardized securities that are easier to value than the individual, idiosyncratic loans that back the securities $^{2}$. This standardization occurs through several channels. First, credit rating agencies publish and use a standardized process to determine ratings for CLOs and the underlying assets in the loan pools. ${ }^{3}$ For example, assumptions regarding loan recovery in default, an input into the rating process, use standard formulae based on the priority ranking of the loan in the capital structure. Asset managers also provide standardization of the product offered to investors through the collateral restrictions in their organizational documents. These restrictions provide a list of characteristics to which the manager must adhere in assembling the loans in the pool.

A noteworthy feature of this type of standardization is that it is open-ended: while the composition of CLO loan pools, and the process used to generate ratings, is often based on a closed set of loan characteristics, these characteristics do not provide a complete description of the rights and obligations in each loan contract being originated and sold. Loans may

\footnotetext{
${ }^{1}$ For example, the definition of securitization in Investopedia: "Securitization is the process of taking an illiquid asset, or group of assets, and through financial engineering, transforming them into a security...This market is extremely large, providing a significant amount of liquidity to the group of mortgages, which otherwise would have been quite illiquid on their own."

${ }^{2}$ The Encylopedia of Finance (Lee and Lee, 2006) defines securitization as: "Pooling loans for various purposes into standardized securities backed by those loans, which can then be traded like any other security"

${ }^{3}$ See, for example, "Global Cash Flow and Synthetic CDO Criteria", Standard and Poors Structured Finance, March 21, 2002. In addition, rating agencies license computer programs to CLO asset managers that allow these managers to generate predicted ratings for their CLO securities by inputting a pre-determined set of characteristics of their loan pools. (Benmelech and Dlugosz, 2009)
} 
include various clauses and covenants that are not included in these fixed sets; moreover, the specific contractual language may modify the lenders rights in important ways that a standardized rating model may not capture.

The goal of this chapter is to investigate the impact of standardization on the liquidity and composition of financial contracts. Following the property law literature approach (Merrill and Smith 2000, 2001), we model standardization as a technology that reduces the contract reading costs of potential buyers (in our case, buyers of debt contracts, such as CDO investors). Using the same tension as in our earlier work (Ayotte and Bolton 2008), the originator of a loan contract and the borrower may have the incentive to include contractual terms that redistribute value from unknowing third-parties (here, loan buyers) when reading costs are present. Third-parties are rational, and anticipate the possibility of these redistributive terms. As a result, the liquidity of loan contracts in secondary markets is affected, as well as the borrowing and investing decisions of firms.

Our model generates findings that relate to recent developments in credit markets. In particular, one trend accompanying the recent boom in loan securitization was the rapid weakening of contractual covenants in loan agreements. This trend, which has become known as covenant-lite lending, became commonplace during the boom in loan securitization, and has become substantially less common as the securitization market has slowed. Our model explains this empirical correlation. When an open-ended standardization technology is introduced to a market, it becomes cheaper to disclose information about certain features of a contract at low cost. If these features reveal enough about the loan, the loan may be sold without any further investigation by the buyer. If she has rational expectations, however, the loan buyer will anticipate that the loan originator and borrower will write the contract so that all of the unobserved terms of the contract are unfavorable to her. The buyer's willingness to pay will be based on the expectation of a covenant-lite contract.

We find that under open-ended standardization, two equilibria are possible. In one equilibrium, covenant-lite contracts are written and sold in secondary markets. These contracts are more liquid because they reduce reading costs for buyers, but because of their covenantlite features, they fail to limit over-borrowing and excess continuation by the borrowing firm in bad states of the world. This equilibrium is more likely in good times (when good states are expected in the future with high probability), because the costs of moral hazard created by covenant-lite loans arise only when bad states of the world occur. 
If the benefits of liquidity are low or agency costs are high, a second equilibrium is possible, with covenant-strong contracting and illiquid loans that are held by the originator. In this equilibrium, the secondary market for loan sales is subject to the familiar "lemons problem". Beliefs are such that any loan that is sold is believed to be covenant-lite, and thus subject to a large price discount. Knowing this, the originator instead chooses to write a more valuable, covenant-strong contract that prevents over-borrowing in the bad state of the world, holding this loan to maturity. Thus, our model rationalizes the perspective of Standard and Poors, who wrote, presciently, about the covenant-lite lending trend in 2007:

"Liquidity has helped the loan market evolve from strictly buy-and-hold to a trading market, making covenants less compelling. When a lender held a loan for the duration, the ability to control the situation was much more important than it is now, when the secondary market is fairly liquid...Right now, with default rates at record lows and borrowers generally able to buy covenant relief on the cheap, there is little cost in giving up [typical covenants absent in covenant lite loans]. In the future, however, when the cycle turns, lenders will grow more demanding." 4

Our model is intended to serve only as a starting point to investigate these issues, but we expect that further investigation may generate additional insight in future work. For example, the standard logic in finance is that senior securities should be the most liquid, because their value is less sensitive to private information about the firm's future cash flows (Gorton and Pennacchi 1990). In our model, the source of asymmetric information is the terms in the debt contract. When contractual terms become the source of asymmetric information, one might expect that a senior loan would be less liquid than a junior loan (or equity), because an effective guarantee of seniority requires a host of specific covenants to create it, while an absence of seniority does not. Thus, senior loans may require greater investigation by lenders than junior loans with respect to the details of the contract.

\footnotetext{
4 "CDO Spotlight: The Covenant-Lite Juggernaut Is Raising CLO Risks - And Standard \& Poor's Is Responding" Standard and Poors Ratings Direct, June 12, 2007.
} 


\section{Related Literature}

The liquidity benefits of standardized contracts due to lower reading costs has been posited in the financial economics literature, and associated with securitization (Amihud and Mendelson 1988). But to our knowledge, the trade-offs from the issuer's perspective have not been formalized. The formal theoretical economics literature on standardization to date, in our view, can be viewed alternatively as theories of contractual innovation. The primary tradeoffs in these works relates to the choice between an existing set of contracts with well-known properties, and the innovation of a new contract with potentially valuable but also potentially unknown features.

Sussman (1999) studies the decision of a potential innovator to create a new contract, at a privately incurred cost. New contracts can be valuable in this model by allowing more efficient risk-sharing across states than the existing, standard contracts provide. The innovator, whose monopoly over the new contract is only temporary, can not recoup the entire value of the new contract. Thus, under-innovation occurs, and the extent of new innovation depends on the characteristics of the existing standard contracts.

Gale (1992) is closer to our model, in that potential buyers must incur costly investigation to understand the full implications of contracts. In Gale's model, the potential buyer investigates his own utility function, rather than the contract itself, to find out whether the new contract's features are well-adapted to his preferences. Multiple equilbria can arise due to network efficiencies in sharing the idiosyncratic risk of a new security. If a potential buyer expects others to investigate, then he may investigate as well, because he can share the idiosyncratic risk of the new security with other buyers. If he expects others will not investigate, then he might not investigate either and choose to hold standard securities whose properties are well-known.

Empirical evidence in Rajan, Seru and Vig (2008) is closely related to some of the tradeoffs we model here. Rajan, Seru and Vig (2008) find that the increasing prevalence of loan securitization resulted in two related forces. First, loan interest rates became more closely tied to easily describable, standardized "hard information" such as borrowers' credit scores

and the loan-to-value ratio. At the same time, models that predict default based on these variables, using data from a regime with low securitization, under-predicted default rates when securitization became more prevalent. These authors hypothesize that lenders spent less time and effort gathering information that is more costly to observe by the ultimate 
loan buyers ("soft information" such as subjective evaluation by a loan officer), since the originating lenders planned on selling these loans. Our model considers the possibility that hidden information is in non-standardized contractual terms, instead of borrower characteristics. Also, loan buyers in our model are rational and do not misprice loans in equilibrium. Nevertheless, our model does predict that the prices of sold loans will depend more on standardized information, and non-standardized, hidden information will be unfavorable to the ultimate loan buyer.

\subsection{A brief summary of Ayotte and Bolton (2008)}

This chapter follows closely from our earlier work on optimal property rights in financial contracting (Ayotte and Bolton 2008). In that paper, the key tension arises because a later lender (P2) must expend a cost to observe pre-existing rights in a borrower's (A's) property that were transferred by contract to an earlier lender (P1). Since A ultimately internalizes these reading costs, he would like to reduce them by committing to P2 that assets will be available to repay his loan.

This commitment is not possible without the law, however. P2 is unwilling to lend without expending reading costs because he is aware that $\mathrm{P} 1$ and $\mathrm{A}$ have an incentive to collude against him if he does not. They might write a contract, for example, that transfers all of A's rights in his assets to P1, making them unavailable to satisfy P2's claim when it comes due. With this in mind, P2 insists that A reimburse a sufficient level of due diligence expenditures to assure P2 that there will be sufficient cash flows available to pay him at the final date. The due diligence reimbursement serves as a valuable signal: if $\mathrm{A}$ is willing to help P2 investigate into his prior contracts, he must believe that P2 will lend after the investigation.

The law provides a credible commitment that reduces these costs of investigation and credit rationing. If $\mathrm{P} 2$ is confident that the law will refuse to enforce a transfer of rights that is particularly damaging to him, he might be willing to lend after a less costly investigation. In equilibrium, this makes A better off.

Our model generates several comparative statics that drive optimal legal restrictions on property rights. In particular, we find that an optimal law refuses to enforce transfers of rights to $\mathrm{P} 1$ by $\mathrm{A}$ when these rights are a) more costly to observe, b) less likely to reduce A's agency costs, and c) more redistributive from P2. 
This chapter builds from our earlier work, but the key tension is not between an early lender and a later lender, but instead between the early lender and a loan buyer. In this chapter, standardized contracts serve a role similar to legal restrictions in our earlier work, in that they provide a minimum guarantee to a loan buyer and thus make the loan buyer more willing to participate. To our knowledge, standardization has not been modeled as a means of providing this commitment.

\section{Model}

\subsection{Technological assumptions}

We extend our model of a firm in Ayotte and Bolton (2008) comprising a single project that requires two rounds of financing from two different lenders. At date 1, a wealthless agent $(A)$ is endowed with a valuable idea, and must raise an amount of $i_{1}$ from a principal $(P 1)$ to start the project. To continue the project at date 2 , the agent requires an additional cash input of $i_{2}$ from a second principal $(P 2)$. To focus on the interface between principal $P 1$ 's and $P 2$ 's claims, we shall make the restrictive assumption that $P 2$ can contribute no more than the required investment outlay $i_{2}$ and that $P 1$ can not contribute the entire amount $i_{1}+i_{2}$. Between dates 1 and 2 (call this date 1.5), $P 1$ may suffer a liquidity shock, described in detail below. Also, both principals operate in competitive lending markets, all parties are assumed to be risk-neutral, and there is no discounting.

If the project receives two rounds of financing (i.e. it is continued at date 2 rather than liquidated) it produces a random cash flow at date 3. If the project does not receive the required funding at date 2 , it is liquidated for a known value $L>0$. The final cash flow outcome depends on the realization of the state of nature at date 2, which becomes observable to $P 2$ and $A$ at date 2 before the continuation decision is made. We allow for two states of nature, $\hat{s} \in\left\{s_{g}, s_{b}\right\}$. The good state of nature, $s_{g}$, occurs with probability $\pi$ and the bad state, $s_{b}$, with probability $1-\pi$. As is standard in this literature, we assume that $\hat{s}$ is non-contractible.

In the bad state of nature, the project yields a cash-flow of $X$ at date 3 with probability $p$ and with probability $(1-p)$ the project yields no cash flow but a liquidation value $\gamma L$, where $\gamma<1$. In the good state of nature, the cash-flow outcome of the project depends on the agent's effort choice $e \in\{0,1\}$ at date 2 . If the agent chooses $e=1$ then the project 
yields a final cash flow $X$ with certainty. If the agent chooses $e=0$, the project succeeds with probability $p$, as in the bad state of nature. The agent's private cost of choosing high effort $(e=1)$ is $c>0$, and the cost of $e=0$ is normalized to zero.

\subsection{Parameter assumptions}

The parameter assumptions are identical to Ayotte and Bolton (2008); we repeat them here for convenience. We shall restrict ourselves to a subset of parameter values for which the optimal contract for $P 1$ and $A$, and for $P 2$ and $A$, is such that continuation with high effort is optimal in the good state and liquidation at date 2 is optimal in the bad state.

For ease of exposition, we will use the notation $R_{g}$ to denote the maximum pledgeable income to $P 1$ in the good state, conditional on continuation with effort:

$$
R_{g} \equiv X-\frac{c}{1-p}-i_{2}
$$

To see that this is the maximum pledgeable income to $P 1$, note that in order to encourage $A$ to choose high effort, $A$ requires a sufficient stake $w_{g}$ in the output when the project succeeds. An optimal contract will pay the agent $w_{g}$ when the cash flow is $X$ and 0 if output is 0 . Thus, in order to elicit effort from $A$, the following incentive compatibility constraint must be satisfied:

$$
w_{g}-c \geq p w_{g}
$$

which reduces to

$$
w_{g} \geq \frac{c}{1-p} .
$$

Therefore, the maximum pledgeable income to all lenders is $X-\frac{c}{1-p}$. Since $P 2$ will not participate unless he receives an expected payment equal to his monetary contribution, $P 2$ must be repaid $i_{2}$. Thus the maximum pledgeable income to $P 1$ is as in (1).

With this notation, the parameter restrictions we maintain throughout the paper are:

\section{Assumptions:}

\section{A1)}

$$
X-c-i_{2}>L
$$


The first assumption tells us that in the good state, continuation with high effort is economically efficient relative to liquidation.

A2)

$$
p X+(1-p) \gamma L-i_{2}<L
$$

Assumption A2 says that continuation with low effort is inefficient relative to liquidation; hence liquidating the project will be optimal in the bad state at date 2. Assumptions A1 and A2 together imply also that high effort is efficient relative to low effort in the good state.

A3)

$$
\pi R_{g}+(1-\pi) L \geq i_{1}
$$

Assumption A3 implies that the first-best action plan, which involves continuation in the good state with effort and liquidation in the bad state, can generate enough cash flow to repay $P 1$ for his loan. Since we assume that $L<i_{1}$, A3 also implies that $R_{g}>L$; i.e. continuation with effort produces more pledgeable income to $P 1$ than liquidation in the good state.

Finally, we shall also assume that:

A4)

$$
X-R_{g} \geq \frac{i_{2}}{p} .
$$

As we will show in the next section, assumption $\mathbf{A 4}$ implies that $P 1$ may be at risk of dilution of his claim in the bad state if he writes a debt contract that makes him senior to $P 2$, but does not limit $P 2$ 's borrowing. This assumption implies that $P 1$ will require a negative covenant in his loan contract in addition to seniority in order to elicit the first-best action plan by $A$.

\subsection{Contracting assumptions}

The agent $A$ and principal $P 1$ can write a bilateral long-term debt contract $C_{1}=\left\{i_{1}, F_{1}, \xi_{1}, \Phi_{1}\right\}$ at date 1 . Similarly, the agent and principal $P 2$ can write a bilateral debt contract $C_{2}=$ $\left\{i_{2}, F_{2}, \xi_{2}\right\}$ at date 2. Each bilateral contract specifies the amount the principal agrees to lend $i_{j}$ and a repayment $F_{j}$ at date 3 . The contracts can also specify whether $P 1$ takes a security interest in the final cash flow or not $\left(\xi_{j} \in\{0,1\}\right.$, where $1=$ secured, $0=$ unsecured). Consistent with U.S. debtor-creditor law, a security interest gives the lender seniority over 
any unsecured lender, and seniority over any other secured lender that arrives later in time. ${ }^{5}$

Most important to this chapter, the contract between $P 1$ and $A$ can also include a negative covenant, which states a maximum amount $\Phi_{j}$ that $A$ is allowed to repay any subsequent lender at date $3 .{ }^{6} \mathrm{We}$ assume that this negative covenant gives $P 1$ a property right that is good against $P 2$ : if the negative pledge is violated by $P 2^{\prime} s$ loan, then $P 2^{\prime} s$ loan would be voided, giving him no rights to collect from $A$. In this chapter, unlike Ayotte and Bolton (2008), P2 is assumed to be fully aware of $P 1$ 's loan with no reading costs. In contexts where $P 2$ has actual knowledge, negative covenants have been enforced against subsequent lenders as property rights.

We also rule out the possibility for now that $P 1$ is available to monitor the firm, or to renegotiate his contract with $A$ at date 2 after the realization of the state of nature $s_{l}$. Thus, $P 1$ is a passive lender who can only lend at date 1 and collect at the final date. This assumption is admittedly strong, but is made to demonstrate in the simplest possible fashion the potential conflicts between $P 1$ and $P 2$ when they lend at different points in time.

The key economic issues in this chapter are as follows. First, the agent's repayment obligations $F_{j}$ must be low enough that the agent has an incentive to put in high effort $(e=1)$ in state $s_{g}$. Second, $F_{1}$ must be sufficiently low to make room for continuation financing by $P 2$ at date 2, whenever continuation is efficient. Third, $P 1$ faces a threat of dilution of the value of his claim $F_{1}$ in the bad state at date 2 , when the agent issues a new claim $F_{2}$ to $P 2$. As we show below, making $P 1$ senior to $P 2$ is not a sufficient protection against dilution in our setup, so a negative covenant in $P 1^{\prime} s$ contract will be necessary to prevent inefficient dilution.

\subsection{Liquidity Preferences and Loan Sales}

In this chapter, we restrict consideration in the formal model to the liquidity demand of $P 1$, which is modeled as follows. At date 1.5, after signing contract $C_{1}$ but before the state of nature $\hat{s} \in\left\{s_{g}, s_{b}\right\}$ is realized, $P 1$ requires cash (perhaps to originate new loans) and thus values the ability to sell the loan. Formally, we assume that any payment $P 1$ receives after date 1.5 is discounted by a factor $\delta<1$ : a contract worth $V$ to an outside buyer with no

\footnotetext{
${ }^{5}$ This implies that if $A$ gives security interests to both lenders, $P 1$ has priority over $P 2$ by virtue of being first in time.

${ }^{6}$ Since $P 2$ is the last lender in our simple model, this term is obviously relevant only for $P 1$.
} 
liquidity needs is worth $\delta V$ to $P 1$. The liquidity demand of $P 1(\delta)$ is known to all parties at date 1.

We assume a competitive market of potential loan buyers (call a buyer B1) with no liquidity needs, willing to buy loans at their perceived fair value at date 1.5. These investors can be thought of as investors such as pension fund managers or other investors that purchase CDO securities. Key to our problem, though, these buyers are imperfectly informed about the details of the loan contracts offered for sale. If $P 1$ and $A$ expect that $B 1$ is willing to pay a high enough price, they might water down the terms of the loan agreement through weak covenant protection, knowing they can sell it to $B 1$ at an inflated value. We assume that $P 1$ and $A$ can act as a coalition that maximizes their joint surplus. That is, any benefit to $A$ from cheating $B 1$ can be shared with $P 1$ through side payments. ${ }^{7}$

To keep the problem simple, we make two strong assumptions about the relationship between the loan buyer $B 1$ and seller $P 1$. First, we assume that although $B 1$ is aware of the production technology of the firm (i.e. the parameters $X, p, \pi$, etc), he is completely uninformed about the specifics of the loan contract $C 1$ in the absence of any standardization. The lack of information about loan contracts is realistic in the securitization context, in which many investors hold small stakes in many individual loans. CDO issuances are often backed by hundreds of loans, many of which are purchased by asset managers after the CDO securities are issued to investors. It is rare for a CDO investor to examine the individual loan contracts that comprise the loan pool; instead, these investors are likely to rely on standardized information, such as credit ratings and the prospectus that describes the key characteristics of the individual assets.

Second, in restricting $B 1$ to buy the entire loan or nothing, we abstract from any contracting between $P 1$ and $B 1$, which is undoubtedly important in practice. In many securitizations, for example, the loan originators hold equity in the SPV as a means of eliminating the asymmetric information problems that are relevant here. Though optimal contracts between loan buyers and sellers can mitigate these problems, recent developments suggest that they do not eliminate them.

\footnotetext{
${ }^{7}$ One way to motivate this scenario is through an "origination fee" that $A$ pays $P 1$. Another is a second loan that $P 1$ holds rather than sells.
} 


\section{Optimal Contracting with no information costs}

\subsubsection{First-best contract}

Suppose a benevolent, social welfare-maximizing planner could observe the state of the world and make all investment and effort decisions. Under the assumptions above (A1-A4), the social planner would choose to fund the project, to continue the project in the good state at date 2 while at the same time choosing high effort $(e=1)$, and to liquidate the project at date 2 in the bad state. This first-best action plan would maximize social welfare, which is given by

$$
\pi\left(X-c-i_{2}\right)+(1-\pi) L-i_{1}
$$

Even though the state of the world is not contractible, in Ayotte and Bolton (2008), we show that the following contract will result in a first-best outcome:

Proposition 1 Under assumptions $\boldsymbol{A} 1$ to $\boldsymbol{A}$, an optimal contract between $P 1$ and $A$ is the following: $A$ receives $i_{1}$ at date 1 , and promises $P 1$ a repayment

$$
F_{1}=\frac{i_{1}-(1-\pi) L}{\pi}
$$

at date 3. P1 takes a first-priority security interest in the final cash flow, and P1 has a right to void any loan to $A$ made before date 3 whose repayment exceeds $\Phi_{1}=i_{2}$.

The best response for $\mathrm{P} 2$ and $A$ at date 2 is to sign a new loan contract only in the good state specifying a loan of $i_{2}$ in return for a (riskless) junior claim of $i_{2}$ at date 3 .

Proof. see Ayotte and Bolton (2008).

In order to implement the first-best, $P 1$ requires not only priority over $P 2$ (through the security interest), but also that $A$ make a credible commitment not to borrow more than $i_{2}$. If this negative pledge were not included, then in any contract that allows for continuation with effort in the good state, $P 2$ and $A$ would have the incentive to continue the firm inefficiently at $P 1^{\prime} s$ expense in the bad state.

To see this, recall that under assumption $\mathbf{A 4}, X>R_{g}+\frac{i_{2}}{p}$. To achieve continuation with effort in the good state $F_{1}$ must be no larger than $R_{g}$, leaving $X-R_{g}>\frac{i_{2}}{p}$ available to offer to $P 2$. In the bad state, $P 2$ would be willing to lend $i_{2}$ and take an unsecured (junior) 
debt claim with face value $F_{2}=\frac{i_{2}}{p}$. Then $A$ would then receive an expected payoff from continuation of

$$
p\left(X-F_{1}-F_{2}\right)>p\left(X-R_{g}-\frac{i_{2}}{p}\right)>0,
$$

which is strictly higher than what $A$ gets in liquidation.

A negative pledge clause that limits $P 2^{\prime} s$ repayment to $i_{2}$ prevents this excess continuation problem. Since $P 2$ understands that $A$ can offer no more than $i_{2}, P 2$ is willing to lend in the good state (since repayment occurs with certainty) but not in the bad state (since the possibility of failure requires a face value above $i_{2}$ ). Thus, the negative pledge clause makes the first-best outcome achievable even though the state is non-contractible. ${ }^{8}$ We will refer to the first-best contract between $P 1$ and $A$ in Proposition 1 as a covenant-strong contract since it includes the negative pledge, and denote this contract $C_{1}^{f b}$.

\section{Optimal Contracting}

\subsection{The contracting and trading game with no standardization}

To recap, the timing of the contracting game proceeds as follows:

1. At date $1, P 1$ and $A$ agree on a contract $C 1$ and $P 1$ extends a loan of $i_{1}$ to $A$.

2. At date 1.5, $P 1$ decides whether to sell his loan to $B 1$. The loan sale game works as follows:

a. B1 forms a belief about the loan contract. Let $\nu_{1}$ denote this belief.

b. P1 decides whether or not to make a take it or leave it offer to sell his loan to B1. An offer is a price $y_{1}$ at which the loan will be sold if $B 1$ agrees.

c. If an offer is made, B1 examines the contract and updates his belief to $\nu\left(\Omega_{1}\right)$ based on $\Omega_{1}$, the observable component of the contract $C_{1}$. B1 then decides whether or not to buy the loan at the given price.

3. At date 2, all parties observe the state of the world. $A$ approaches $P 2$ to negotiate

\footnotetext{
${ }^{8}$ If $P 2$ can take a claim on $A$ 's personal assets (his dividend from the firm at the end of date three) then he would be equally happy to lend into an inefficient continuation in the bad state. Thus $P 1$ 's right to restrict alienability must extend beyond the corporate form and also to $A$ 's assets more generally in order to effectively shut down P2's loan.
} 
contract $C 2$. If $P 2$ lends $i_{2}$, then the project continues to date 3 . Otherwise, the project liquidates.

4. At date 3, if the project was continued, cash flows are realized and the parties holding loans collect from $A$ according to the rights specified in their contracts.

We assume that the loan buyer has pessimistic beliefs. Specifically, the buyer's belief function $\nu\left(C_{1}\right)$ assumes that the contract being sold is as unfavorable to the buyer as possible, given the loan characteristics that the buyer observes. While these beliefs are convenient, they are not crucial to our qualitative results.

With this structure in hand, it is easy to see that loans will be illiquid when buyers are uninformed. We formalize this in the following proposition:

Proposition 2 Under no standardization, loans are illiquid and covenant-strong: there does not exist any pure strategy Perfect Bayesian Equilibrium with loan sales. P1 and A write the first-best contract $C_{1}^{f b}$.

The intuition for the first part of the proposition is simple. If the buyer observes nothing about the loan he buys, and his beliefs are pessimistic, he will assume that any loan offered for sale is worthless. Given these beliefs, $B 1$ is not willing to pay any positive price. This, in turn, makes $P 1$ willing to forgo any attempt to sell the loan.

The implications of illiquid secondary markets has an important effect on the details of the loan contract actually written between $P 1$ and $A$. Since $P 1$ expects the loan to be illiquid, the contract between $P 1$ and $A$ is written without regard to the buyer-this implies that the parties will write the first-best contract. ${ }^{9}$

We now turn to an analysis of open-ended standardization and its effects on optimal contracting.

\footnotetext{
${ }^{9}$ The result may seem paradoxical, in that the loan buyer's pessimistic beliefs about a worthless loan are not confirmed by the loan that $P 1$ and $A$ actually write. Moreover, $P 1$ loses liquidity by virtue of $B 1^{\prime} s$ beliefs: on the equilibrium path, there are potential gains from trade that are not exploited when $P 1$ suffers a liquidity shock. But the perfect bayesian equilibrium (PBE) requires only that strategies are consistent with beliefs on the equilibrium path. $P 2$ believes that any loan offered for sale is worthless; given these beliefs, $P 1$ refuses to offer the loan for sale, knowing any positive price will be rejected.
} 


\subsection{Optimal Contracting with Open-Ended Standardization}

We model open-ended standardization as follows. Suppose a technology exists that allows the loan buyer to observe some, but not all, characteristics of the loan he buys at a low cost. As before, this assumption is intended to capture the type of standardization process involved in the securitization of bank loans. When a collateral manager assembles a loan portfolio, he creates a prospectus for investors that describes certain characteristics of the loans that will be assembled in the pool. This provides some important information to investors, who need not read the details of every loan contract purchased by the pool.

In our model, suppose that this technology allows the loan buyer, at zero cost, to observe $i_{1}, F_{1}$, and $\xi_{1}$, but not $\Phi_{1}$. In other words, the loan buyer knows the interest rate and whether the loan is secured (and thus senior), but is not aware of the specific contractual covenants in the loan that are intended to prevent excess continuation in the bad state.

Unlike the previous case, under open-ended standardization the loan buyer can be guaranteed that the minimum value of the loan is above zero. Specifically, the minimum value of a loan at date 1.5 that is secured, and has face value $F_{1} \leq R_{1}$ is

$$
V_{\text {lite }}\left(F_{1}\right)=\pi F_{1}+(1-\pi)\left(p F_{1}+(1-p) \gamma L\right)
$$

$V_{\text {lite }}$ is the minimum value that $B 1$ can ascribe to the loan when $P 1$ offers to sell it at date 1.5. Given what $B 1$ can observe, the worst case scenario is a contract that completely omits the negative pledge term $\Phi_{1}$, thus allowing $A$ to continue inefficiently in the bad state

and diluting $B 1$. Call this contract $C_{1}^{l i t e}$. Alternatively, the first-best loan contract $C_{1}^{f b}$ has the following value to the buyer:

$$
V_{f b}\left(F_{1}\right)=\pi F_{1}+(1-\pi) L
$$

Compared to the no-standardization case, open-ended standardization provides more of a guarantee about the loan's characteristics and limits the asymmetric information between loan buyer and seller.

Now, consider how $P 1$ and $A$ will set $F_{1}$. To keep the problem simple, we suppose that $F_{1}$ is set at the level that allows $P 1$ to break even under a covenant-lite contract, whenever $P 1$ plans to offer a loan for sale. If $P 1$ writes a covenant-lite contract, then continuation will not be prevented in the bad state, so the face value of the debt $F_{1}^{l}$ satisfies 


$$
i_{1}=\pi F_{1}^{l}+(1-\pi)\left(p F_{1}^{l}+(1-p) \gamma L\right)
$$

Rearranging, we get

$$
F_{1}^{l}=\frac{i_{1}-(1-\pi)(1-p) \gamma L}{\pi+(1-\pi) p}
$$

When $P 1$ plans to hold the loan, $F_{1}^{s}$ is set so that $P 1$ breaks even given that the contract is covenant-strong:

$$
F_{1}^{s}=\frac{i_{1}-(1-\pi) L}{\pi}
$$

As a result, the loan market can now become more liquid as the next proposition illustrates.

Proposition 3 Under open-ended standardization, two pure strategy equilibria are possible: an equilibrium with liquid, covenant-lite loans, and an equilibrium with illiquid, covenantstrong loans.

Consider the observable components of the contract $C_{1}:\left\{i_{1}, F_{1}, \xi_{1}\right\}$. Effectively, this allows $B 1$ to know the interest rate and whether the loan is secured, but not whether the loan includes the negative pledge covenant. Given this contract and B1's beliefs, the buyer is willing to pay $V_{\text {lite }}\left(F_{1}\right)$ if the loan is offered for sale, which assumes that the covenant is missing (or completely ineffective).

Now, consider the incentives of $P 1$ and $A$ when they write $C_{1}$. Two cases are relevant. First, suppose that the cost of liquidity to $P 1$ is small relative to the difference in values between a covenant-lite and covenant-strong loan. Call this Case 1:

$$
\delta V_{f b}\left(F_{1}^{s}\right)>V_{\text {lite }}\left(F_{1}^{s}\right)
$$

Then, if $P 1$ has a covenant-strong contract, he prefers to hold it and suffer the liquidity cost rather than sell it, given $B 1$ 's beliefs that the contract is covenant-lite. In this case, the trade-off in writing a covenant-strong contract is the liquidity cost to $P 1$. The benefit is the expected gains from preventing inefficient dilution in the bad state. Thus, the incentive compatibility condition under which $P 1$ and $A$ write a covenant-lite contract is given by ${ }^{10}$

\footnotetext{
${ }^{10}$ If the expression holds at $F_{1}^{s}$, it holds a fortiori for $F_{1}^{l}$, which will be the equilibrium $F_{1}$ in a covenant-lite equilibrium.
} 


$$
\begin{aligned}
(1-\delta) V_{f b}\left(F_{1}^{s}\right)> & (1-\pi)\left(L-p X-(1-p) \gamma L+i_{2}\right) \\
& \text { or } \\
(1-\delta)\left(\pi F_{1}^{s}+(1-\pi) L\right)> & (1-\pi)\left(L-p X-(1-p) \gamma L+i_{2}\right)
\end{aligned}
$$

The left hand side is the expected liquidity cost to the $P 1$ and $A$ coalition from holding a loan when a liquidity shock occurs. The right hand side is the expected efficiency loss from continuation in the bad state, which $P 1$ and $A$ bear in equilibrium. If the inequality holds, then $P 1$ and $A$ would prefer to write a covenant-lite contract, which is sold whenever $P 1$ suffers a liquidity shock, at a fair price. If this inequality does not hold, then the equilibrium will feature covenant-strong, illiquid contracts.

The second case (Case 2) occurs when P1's liquidity demand is large enough that P1 would prefer to sell a covenant-strong loan even if it is subject to the discount due to B1's pessimistic beliefs. This will be true when $\delta V_{f b}\left(F_{1}^{s}\right)<V_{\text {lite }}\left(F_{1}^{s}\right)$. Then the above inequality becomes

$$
V_{f b}\left(F_{1}^{s}\right)-V_{\text {lite }}\left(F_{1}^{s}\right)>(1-\pi)\left(L-p X-(1-p) \gamma L+i_{2}\right)
$$

If this inequality holds, then $P 1$ and $A$ prefer to write a covenant-lite contract which is sold when $P 1$ suffers a liquidity shock, at a fair price. This expression can be reduced to

$$
X-F_{1}^{s}>\frac{i_{2}}{p}
$$

which is always true, given assumption A4. Thus, the parties always prefer a covenantlite contract if liquidity demand is high enough.

Corollary 4 The liquid, covenant-lite equilibrium is more likely when:

a) the probability of the bad state is lower (higher $\pi$ );

b) originators' liquidity needs are higher (lower $\delta$ )

When economic times are good, and defaults are unlikely to occur, loan buyers are less concerned about the absence of contractual terms that would impose discipline on borrowers in bad states. As a result, there are two effects: they are willing to pay a high price for loans, 
despite their information disadvantage. This makes Case 2 more likely to occur, which is a covenant-lite equilibrium. Second, within the Case 1 region, a covenant-lite equilibrium occurs if and only if

$$
(1-\delta)\left(\pi F_{1}^{s}+(1-\pi) L\right)>(1-\pi)\left(L-p X-(1-p) \gamma L+i_{2}\right)
$$

Given the definition of $F_{1}^{s}$, the left-hand side of the inequality is always equal to $(1-\delta) i_{1}$, which is independent of $\pi$. The right-hand side is the expected efficiency loss from excess continuation in the bad state, and is decreasing in $\pi$. This implies that the covenant-lite equilibrium is more likely to occur when $\pi$ is high. Intuitively, within Case $1, P 1$ and $A$ trade off the cost of holding an illiquid, covenant-strong loan contract with the expected losses from inefficient continuation. As $\pi$ rises, the costs of inefficient continuation fall.

Part (b) of the Corollary is also important. The liquidity discount can be interpreted as a cost to $P 1$ of funds required for new lending. In boom periods (when $P 1$ has valuable loan opportunities), selling loans is more valuable because it frees up capital to make new loans (Drucker and Puri 2006). Thus, we would expect $\delta$ to be high during a credit boom, when lenders perceive that the opportunity cost of funds is high. Thus, as credit markets deteriorated in 2007, loan opportunities dried up and bad states became more likely. Our model explains that both of these conditions lead to more covenant-strong lending with less liquidity.

The formal model is intended as a starting point to investigating these issues. In the next section, we give some intuition for how the model might be extended, and some complications.

\subsubsection{Sales of junior loans}

In the formal model, we considered sales of $P 1^{\prime} s$ senior loan to an outside buyer. Suppose instead that $P 2$ has liquidity needs $(\delta<1)$ with respect to its junior loan. $P 2$ seeks to sell her loan in a competitive secondary market to some buyer B2 at an interim date 2.5 (between the date of $P 2^{\prime} s$ loan and the final cash flow).

Similar to our analysis above, suppose there are no information asymmetries with respect to $P 1^{\prime} s$ loan-all parties are fully informed about $C_{1}$, but $P 2$ has private information about $C 2$. Consider the incentives of the various parties under open-ended standardization. Specifically, suppose a loan buyer $B 2$ can observe the standard terms $\left\{i_{2}, F_{2}\right\}$ but not whether the loan is secured $\left(\xi_{2}\right)$ or any negative pledge covenants $\left(\Phi_{2}\right)$. 
Under these assumptions, we expect that the first-best contracts will be written by $P 1$ and P2. P2 lends only in the good state, since the negative pledge in the first-best contract $C_{1}^{f b}$ makes it unprofitable for $P 2$ to extend a loan in the bad state. When $P 2$ lends in the good state, his loan will be fully liquid: $P 2$ will always be able to sell the loan to $B 2$ at its fundamental value $\left(i_{2}\right)$. The intuition for this is simple. Unlike the senior loan $C_{1}$, which requires several contractual terms to guarantee its value, the optimal contract $C_{2}$ is unsecured debt, and does not contain a negative pledge covenant. Thus, there is less scope for opportunism in the contractual terms of a junior loan than there is in a senior loan. The buyer expects a worst-case scenario given the terms he observes, but with a junior loan, the worst-case scenario is in fact the optimal contract.

The idea that junior loans are always liquid, while senior loans can be illiquid, runs against standard theories in corporate finance that find the opposite (Gorton and Pennacchi 1990). When asymmetric information concerns the firm's future cash flows, senior securities are more liquid because their value is less sensitive to private information. In this model, the asymmetric information is about the terms of the contract, not the firm's cash flows. A senior loan requires more contractual terms to be effective. Relative to junior loans, this increases the asymmetry of information between loan buyers and sellers, which can make senior loans particularly illiquid.

This logic is a starting point, but should not be overstated, because we have not fully explored the interactions between loan buyers when there is asymmetric information about both $C_{1}$ and $C_{2}$. Here, the issues become substantially more complicated. A loan buyer $B 2$ would be interested in knowing not only about the details of the contract $C_{2}$ that he is buying, but also about the contract $C_{1}$, which can affect the value of $C_{2}$ in a meaningful way. Moreover, $P 1$ and $A$ will structure their contract in response not only to $B 1$, but also to whether $P 2$ expects to sell his loan to $B 2$. Whether senior or junior loans are more liquid in a more complicated model is left for future work.

\subsubsection{Closed-Ended Standardization}

The open-ended standardization we consider in the formal model assumes that $P 1$ and $A$ can always include in their loan agreement extra terms that $B 1$ can not observe. In the loan securitization context, this is realistic, but it is not true in all cases that involve buying and selling of credit risk. For instance, consider credit default swap contracts. These 
contracts allow one party to purchase credit insurance from another party to protect against a default of some reference entity. These contracts are standardized by the International Swaps and Derivatives Association (ISDA), a trade organization comprised of large players in this market. The ISDA has standard-form contracts that allow the parties to a swap contract to tailor various terms (the price, the reference security, the default event, etc). But importantly, the ISDA form is closed-ended: the options given to the parties to tailor the contract are fixed in advance in the standard contract.

In a richer model, one might expect a trade-off between open- and closed-ended standardization. For example, because of its closed-endedness, terms outside this closed set might be valuable for some borrowers to limit agency costs. But if the standard form becomes open-ended enough to include these terms, and they are sufficiently costly to discover, this increases the scope for contracting parties to include opportunistic terms that redistribute value away from the potential loan buyer.

\subsubsection{Law and standardization}

This chapter focuses on private means of achieving standardization, but has not explored the role of the law in enhancing liquidity of contracts. It is possible for the law to standardize contracts so as to limit asymmetric information about contractual terms, thus making them more liquid.

One example of this is the law's treatment of negotiable instruments under Article 3 of the Uniform Commercial Code (UCC). The intent of this area of law is to enhance the liquidity of loans in the secondary market by limiting the required investigation by a buyer into the loan transaction. Specifically, a loan buyer who qualifies as a "holder in due course" takes free of any "personal defenses" that may be asserted by the borrower (A) against his original lender (P1). For example, suppose that $A$ gives $P 1$ a note in exchange for goods that $P 1$ promises to deliver, and $P 1$ fails to deliver. $P 1$ sells the note to $B 1$, who does not know about $P 1^{\prime} s$ failure to deliver the goods. If $B 1$ is considered a holder in due course, he has the right to collect the full amount of the note from $A$. This frees up $B 1$ from knowing the entire details of the relationship between $P 1$ and $A$ and makes the note more liquid as a result.

The law also adds value in some cases by standardizing the forms of notice that are

available to third parties. Security interests in personal property, governed by Article 9 
of the UCC, is one prominent example. In order to have a right that binds third parties (like buyers and other lenders), a lender must provide notice to the world by recording their interest in a registry that other lenders can check. This notice is standardized and includes only basic information, such as the creditor's name and a categorical description of the collateral subject to the security interest. This standardization has an important benefit in reducing information acquisition costs of third-parties. Suppose, for example, that a lender is interested in being secured by a borrower's inventory. If this lender checks the registry and finds that the only prior security interest is in the borrower's accounts receivable, then the inventory lender knows that she can obtain a first priority position with respect to the inventory; she need not inquire any further into the details of the contract between the receivables lender and the borrower. While there are many other characteristics that would affect the ultimate value of the loan (the borrower's likelihood of default, the lender's expected recovery when her claim exceeds the value of the inventory, etc), the inventory lender can be guaranteed a baseline minimum level of protection at a very low investigation cost. Smith $(2006,2010)$ refers to this concept as modularity, and argues that it is a common observed feature in the standardization of property rights.

While there are examples of standardization within the law that enhance liquidity and limit opportunism, there are important open theoretical questions in this area. As the ISDA and securitization examples illustrate, market participants may have the incentive and ability to create open-ended and closed-ended standardized forms. This raises the question, why is the law necessary to create standardization? Under what circumstances are private attempts to standardize subject to market failures that require legal intervention?

\section{Conclusion}

In this volume, we have conducted a preliminary investigation into standardization of financial contracts as a means of reducing reading costs by third-party loan buyers. We show, however, that standardization is not a panacea. When loan buyers can acquire more information about the underlying loan at low cost, this enhances the liquidity of loan contracts. But this liquidity, in turn, creates incentives for the loan originator and borrower to water down the features of the contract that the loan buyers do not observe. Even if loan buyers

are rational and incorporate the expectation of this "covenant-lite" lending behavior into the 
price of the loan, these terms may be used in equilibrium, particularly when bad economic times are perceived as unlikely. When bad times do arise, however, the absence of covenants that benefit lenders can exacerbate agency problems by borrowers.

We have left many important and interesting questions as open areas for future research. In particular, the role of legal intervention as a mandatory standardization device, and the different ways that standardization can operate, is a promising topic for future theoretical research in law and economics.

Amihud, Y. and H. Mendelsohn (1988). "Liquidity and Asset Prices: Financial Management Implications" Financial Management 17:5-15.

\section{References}

[1] Ayotte, K. and P. Bolton (2008). "Optimal Property Rights in Financial Contracting" Working Paper.

[2] Benmelech, E. and J. Dlugosz (2009). "The Alchemy of CDO Credit Ratings" NBER Working Paper 14878.

[3] Drucker, S. and M. Puri (2009) "On Loan Sales, Loan Contracting, and Lending Relationships" Review of Financial Studies 22(7): 2635-2672

[4] Gale, D. (1992). "Standard Securities" Review of Economic Studies 59:731-755

[5] Lee, C. F. and A.C. Lee (2006). Encyclopedia of Finance. Springer Science and Business Media, Inc.

[6] Merrill, T. and H. E. Smith (2000) "Optimal Standardization in the Law of Property: The Numerus Clausus Principle" Yale Law Journal 110(1): 1-70.

[7] _____ (2001) "What Happened to Property in Law and Economics?", Yale Law Journal 111: $357-398$.

[8] Rajan, U., A. Seru and V. Vig (2008) "The Failure of Models that Predict Failure: Distance, Incentives and Defaults" Working Paper.

[9] Smith, H. E. (2006) "Modularity in Contracts: Boilerplate and Information Flow", Michigan Law Review 104: 1175-1221.

[10] ____. (2010) "Standardization in Property Law" Working paper. 
[11] Sussman, O. (1999) "Economic Growth With Standardized Contracts" European Economic Review 43(9): 1797-1818.

Proof of corollary:

To prove part (a), note that $\frac{\partial}{\partial \pi}\left(\delta V_{f b}\left(F_{1}^{s}\right)-V_{l i t e}\left(F_{1}^{s}\right)\right)<0$. Thus, as $\pi$ rises, we can move only from Case 1 into Case 2, where $\delta V_{f b}<V_{l i t e}$, but not the reverse. The only equilibrium in Case 2 is the liquid, covenant-lite equilibrium. Also, within the Case 1 region, note that the left hand side of the inequality in (3) increases in $\pi$, while the right hand side is decreasing in $\pi$. Thus, the covenant-lite equilibrium is more likely to hold when $\pi$ is higher.

To prove part (b), $\frac{\partial}{\partial \pi}\left(\delta V_{f b}\left(F_{1}^{s}\right)-V_{\text {lite }}\left(F_{1}^{s}\right)\right)<0$ also implies that we can move only from Case 1 into Case 2 as $\delta$ falls, which includes only a covenant-lite equilibrium. Within Case 1 , note that as $\delta$ falls, the LHS of (3) increases, while the RHS does not change. 